\title{
Investigating Sexual Rights and Freedoms of Married Women in Terms of Jurists and Contemporary Jurists
}

\author{
Mahmoud Haeri ${ }^{1}$ \\ ${ }^{1}$ Faculty Member of Yazd University, Iran \\ Correspondence: Mahmoud Haeri, Faculty Member of Yazd University, Iran. E-mail: mhaery@yazd.ac.ir
}

Received: January 21, 2016

Accepted: February 16, 2016 Online Published: March 31, 2016

doi:10.5539/jpl.v9n2p82

URL: http://dx.doi.org/10.5539/jpl.v9n2p82

\begin{abstract}
Family is a safe environment for relaxation of couples. In this safe environment is shaped and nurtured the next generation. Each of these two important functions of the family means satisfy spiritual and emotional needs of couples and raise human generation depends on marital relationships. Islamic law to improve the relationship, for each of the spouses is considered rights and freedoms that by complying them both sides will have the fullest satisfaction of their marriage. As mentioned, these rights are not one-sided and woman has rights in the relationships. Including the right to sleep with a spouse, the right to demand sex from couples, right of liens, and .... In this article we try to investigate some of them in the views of contemporary references.
\end{abstract}

Keywords: wife, couple, sexual, compliance, alimony, right

\section{Introduction}

Is marriage the only source of one side rights for man or woman has rights with this sacred link? Is sexual compliance the only task that in law on the woman's responsibility or double duty? Whether woman could complain in the case of preventing husband from the marital relationship, in court, or only the right of man who forced her to compliance, and if refused, complain? These questions and a thousand other questions may be created in the mind of couple by realizing interest of marriage. The answers that have been given to these questions can be divided into two major categories:

A group including the followers of Judaism and Christianity, as well as the age of ignorance, is considered woman free of rights as the purpose of her creation is only, calming the man. And if we criticize them in reply, hold the verse of the Qur'an that states: " And the symptoms of it is that created for you wives as yourselves to relax with them" So in fact this group considers women as doll and a toy in the hands of man that any man in any amount can play with her, unless she has a right to protest.

But the fact that is considered of legislator is completely different with what they say, because the legislator has introduced the couple to each other's clothes, not just woman as the man's cloth. So each of the spouses in front of each other has the duties and as a result, has rights. We Muslims accept this idea and all references made marital rights equal and mutual not similar to each other. And this is nothing but a manifestation of divine justice.

1) The right of sleeping with the wife:

Sexual pleasure has two aspects, legal and juridical aspect and ethical aspect. In terms of legal and juridical, man has no right over a specified time prevented sexual pleasure of woman. In the traditions also have been warned of man and woman to sexual gratification of each other. Verse 233 of Baghare: "Neither mother nor father, none of them shall loss because of child." A hadith that: "No man or woman has right to refrain the satisfying demand of the sex of opposite side, with the excuse that if sleep with you I'm afraid I'm pregnant and the child deprives of enough milk, or with the excuse of the man, that if I sleep with you, I'm afraid, you become pregnant and I caused the death of my child".

Being bi-sexual need and duty to meet the need from husband is reminded in another verse also clearly. According to the verse of the Koran in Islam, was not allowed to sleep at night during Ramadan, and the couple must refuse during the month of sexual pleasure and intercourse. Muslim youth who had greater sexual need in practice to this provision were unable. Surah Baghareh, verse 187 came to express its permission on the night of Ramadan and said: "On the night of Ramadan, intercourse with your wives was permissible and lawful, because They are your garments and you are their garments "in this verse, male and female were introduced cloth of each 
other, because each side satisfies the other's sexual need, and prevented him from debauchery and arrange each other to chastity.

So the woman must obey and comply against the demand of husband, satisfy his need and prevents debauchery and the husband must fulfill his wife's sexual demand, he helps her in path of chastity. As woman is required to accept his husband demand, the man is also such a task. If a man without a valid reason does not meet the sexual need of his wife and provides the spoil area or hardness of her, he is guilty because he doesn't recognize the duty of good companionship and his wife has right to complain in the court and the judge must force the man to do duty or divorced woman. As in the Koran husband is bound to be well-mannered by his wife and keep her well and good, or with respect and pay out salaries. The man is not allowed to refrain from giving a woman's sexual rights and not divorce her. The order of the Quran: "Keep them well-known or drop them well-known and not hold them to harm and violation of their rights "and "or keep them well or drop with goodness" (Baghareh, 229)

This right is so important that, according to some authorities, if the couple travel to distant city and more than 4 months away from the wife is necessary to return to his hometown in which women living to perform woman's right and sexual intercourse with his wife, unless she avoids the right. (Khoi, $1416 \mathrm{AH}, 299.1)$ And also a decree of nullity condition of not sleeping on permanent contract by couples before marriage and acceptance of the condition by the wife (Ayatollah Azam Golpayegani, 1993, 552.1, Makarem Shirazi and Nouri Hamadani, G.A.Gh / 254)

If a Muslim man without legal excuse and deliberately before religious extent or totally, with his wife not have sexual relationship, in case of complaint of woman is prosecutable and its punishment on the judge's idea (Ayatollah Mousavi Ardebili, 1997, 199.1)

The cause of this sentence: "If a woman marries a man who is not able to have sexual relationship if he wants to terminate the contract should refer to fully qualified judge to judge gives time a year to man, if he could no longer has sexual relationship, then the woman can disturb the contract and not need to divorce "(Ayatollah Safi Golpayegani, 1419 AH, 21/1) The importance is to satisfy wife's sexual need.

Perhaps the cause of focus and attention of the legislator on this issue is that marriage is the only legitimate way to meet the sexual needs of men and women and each woman and man seeking to satisfy sexual needs of each other from this legitimate way. So each of the couple is necessary to accept the demand side, in fulfillment of each other wish and refrain to be into sin and hardness .

By studying the life of the Imams we find that they pay special attention to this important point, as the Imam Sajjad (AS) collected his maid every month and wanted from one of their wives to ask every one of you who does not meet her sexual need, announced to Imam releases her and bring the right person to marry. Imam Sadigh (AS) said: Whoever gathered a group of women that isn't able to saturate them in terms of sex and then they fall into adultery and prostitution, the prostitution guilty is for him.

2) The right to prevent husband pleasure from anus:

One of the differences in Islamic jurisprudence is the issue of cohabitation from anus that there are different opinions about it. What is common among all ideas is respect of this act without permission of woman and what the difference is whether the woman's permission causes losing this action or not?

Some scholars believe in the respect of this act and say even the allowance of woman not cancel the respect and some dislike it (Ayatollah Azam Imam Khomeini, Nouri Hamadani \& Fazel lankarani, 1/2) and others have said such that: sexual intercourse in anus is wrong (Ayatollah Mousavi Ardabili, 1997, 245/1) and some considered leaving it as essential (Ayatollah Tabrizi, G.A.Gh)

If the woman does not permit this action, this non-compliance not cause losing the right of woman charity and men must continue to pay alimony to the woman (Ayatollah Khoi, 1416 AH, 297/1)

Those who permitted this action as the verse 223 of surah Baghareh have appealed that "Your women are your fields so wherever and whatever you want, enter your field" and say this verse for this reason that some people believed, sexual relationship of woman anus is forbidden. In Sunan Abi Dawud and Ibn Abbas narrated that there were husband and wife, of two tribes, the woman from the tribe of the Ansar and the idolaters, while her husband was from Quraysh, and Ansar emulated Jews that were follower of the Book and respect for virtue in science, and many non-Jews imitated and followed the practice of Jews as well as their traits were that not had sexual relationship with woman just from one canal, and it was very pleasing for women and Quraysh tribe had sex with women in any way, from behind and from the front, lying and standing, so that immigrants of Quraysh came to Medina, a man married a woman from the Ansar and went to do the same things, she refused and told that our custom is only from a canal and in one way, if you want, you can, if you will not, be far away now, this 
dispute was revealed and reached to Prophet (PBUH), God sent down this verse (Siyuti, 1986, 263/1)

And opposition responses in rejecting the cause of supporters that: whenever you want, not wherever you want, and if we accept that the meaning of verse is sexual intercourse from anus, if is child from canal.

Ibn Jarir, Ibn Abi Hatam have narrated of Saeed bin Jabir that he said, while I and Mujahid had sat near Ibn Abbas, a man came to him and said, 'Do not you comfort me of the verse? said: Yes. I read: "Ask you about women's menstruation, say it is pain so during menstruation prevents intercourse and do not approach them until they are clean when they clean you can intercourse with them as God has ordered you " (Al-Baghareh / 222) Ibn Abbas said that have sexual relationship with them from the same place where you see blood, as it has already been prohibited sexual intercourse and after cutting blood has sexual intercourse in the same place again. Sael asked: with the verse "Your women are your fields so wherever and whatever you want, enter your field" Why do not you argue? Ibn Abbas said: Woe to you, whether anus of the women is field? If your speech is right, should be abrogated verse 222. Because every time a woman from the front is menstruated you can have sexual relationship from anus, or verse says you should withdraw them? The meaning of verse is any time of night and day, not from any place and in any case (Siyuti, 1986, 1/266)

If we are allowed to not permit a man to have committed this act, must repent and if does it during menstruation, must pay atonement of sexual intercourse, but if this is not done intentionally, that is fine and atonement is not necessary. If we believe to the lack of respect to this relation it must be noted while this intercourse is an evil act that innocents took away of it.

An epicurean narrated from Fath ibn Zayd that he said, I wrote a letter to Imam Reza (AS) and asked about the problem of sexual intercourse with a slave from anus, the answer was, ask someone who has sexual relationship with his slave from anus, you should know that female is a poker that should not suffer, and is the field as God named as field (Samarghandi, 1984, 111/1) and from Abu Basir, from Imam Sadigh (aS) was narrated that he said: avoid not have sexual relationship with gut of women .

And because our laws are derived from our religion, in the Penal Code provided that if a man forced his wife to this practice, recognized as the criminal and woman has the right to sue husband. Because anything that is rejected by Islam certainly is harmful to humans, and it has been proved that from the medical point, this relationship for both parties, especially woman is dangerous. The most important complication that sexual intercourse through anus has for woman is that because true pleasure of sex for the female is through intercourse from vulva and vagina rather than anus, so woman will be with frigidity and lack of sexual interest and in the close future think about herself as a means of burial of her husband's lust and herself not to take pleasure from this God-given instinct.

3) The right not sexual intercourse during menstruation:

One of the cases that legislator is given the right of not compliance to wife, is the request of sexual intercourse during menstruation from the husband. Legislator not only gave women the right to prevent this action, but also the man in the Quran verse clearly is forbidden of this practice, "'Ask you about women's menstruation, say it is pain so during menstruation prevents intercourse and do not approach them until they are clean when they clean you can intercourse with them as God has ordered you " (Al-Baghareh / 222) since the prohibition in the Quran, implying the respect, it is concluded that intercourse with a menstruating woman is forbidden. Of course, man cannot at this time due to lack of compliance of woman, deprived her of alimony (Khoi, $1416 \mathrm{AH}, 297 / 1$ )

This rule may be from legislator due to consideration for the status of women in these days, because menstruating woman is mentally and physically weak and as the verse says a pain to the woman and although that bear this suffering due to physical strength and age is different, however, if at these days, man wants to have sexual intercourse with the woman, the request also add to the stress and physical pressure of woman.

Some of the corruption of intercourse with menstruating is expressed in traditions; Azafar Seirafi said Imam Sadiq (AS) said to me: Do you see those nasty and ugly people? I said: Yes! He said: 'they are the ones who their sperm is formed at the time of menstruation of mothers (Hor Amely, $2012 \mathrm{AH}, 2 / 317$ )

To show respect for this action and prevent man from committing it, in the religious an atonement is considered for committed and recommended that if intercourse is at the beginning of menstruation is paid 18 dinars and if is in the medium of menstruation, 9 dinars is paid and at the end of menstruation $4 / 5$ dinars is paid as atonement. The dinar that paid by the man is the religious ounces of gold, not the common current dinar in practice, but can instead pay dinar, pay the price (Khoi, $1416 \mathrm{AH}, 300 / 1$ )

What is forbidden in the verse of the Quran is sexual intercourse during menstruation in the female vulva, so has the right of other pleasures and if permitted sexual intercourse during menstruation of anus, this practice during 
menstruation is also smooth. As asked Imam Sadiq (AS) the man whose wife is in menstruation what advantages can take of her? He said everything except the front (Kleeni, 2009, 538/5)

This practice is abhorrent that some jurists have ruled: "If a woman cannot become pregnant only during menstruation, and due to pregnancy, conflict and severe hardship form among the couple so that this sin leads to divorce between spouses, it is not permissible for the man to sex in this period with his wife"(Khoi, $1416 \mathrm{AH}$, 299/1)

Expiry of this respect with the words "when cleaned" in the verse is clear, before this expression, "cutting blood" which means blood is cut off. But about "when clean" there is argument that the meaning is to wash the blood or means baptism? According to the hadiths can be sure that it means, wash the blood. As mentioned in a hadith from Imam Sadigh (as), a woman that on the last day her menstruation' blood is cut what is the ruling? He said if his wife is with lust rebellion should wash blood location, then if she wants, he can have sexual relationship before baptism, but baptism is better (Kleene, 2009, 539/5)

4) The right to determine the quality of compliance in temporary marriage:

Upon signing a legal contract, whether permanent or temporary, one right that is created for the spouses is the marital relationship. But in the temporary marriage, the wife can bring down the right of man before or during the contract with her conditions, or is subject to certain qualities.

The advisory opinion No. 7/1760 declared that "the condition of not intercourse in temporary marriage by women is not detrimental to the marriage and contract and condition both are correct, because the condition is not contrary to the requirements of the contract. And the infringement verdict in this law isn't predicted and not has the implementation's guarantee" and, according to Ayatollah Safi Golpayegani view:" This condition is not true, but if the condition is that the wife not intercourse, the permission isn't unlikely. However, if couple with the right conditions do entry, adultery is not considered and punishment depends on the judge view, and if dowry is more, precaution is caused to satisfy the wife "(G.A.q / 1314) Ayatollah Khoei as "not considered the act as adultery, although the couple due to violation of condition, without the consent of the woman is committed of the unlawful act" (1991 p, 105/1) stated that "this condition is true and enforcement of this requirement is the right to terminate the woman in case of violation of man from condition"(Ayatollah Makarem Shirazi, G.a.q / 412)

Ayatollah Mousavi Ardebili has stated that "in temporary marriage, condition of not entry is no problem, but if when her permission is condition can permit on not entry, and if the offense, adultery is not considered and not cause terminated, but, but the offender is guilty and punishable, and if for violation, legal fines like paying money or procuration is in the time period, have to act it".

And if the woman in temporary marriage has the condition that the couple have only the right to sexual relationship and kissing and other games is not right, and he accepted, the bet is void. But if the man does not do it-not that he has no right to do- it is okay (Ayatollah Tabrizi, 1999 Sun, 367/1)

But in permanent marriage, the wife cannot have the condition that the couple not have the right of sexual intercourse, but if she has a condition that not have sexual intercourse-not the couple has the right to have sexual intercourse-the marriage is valid and if later is done by consent of couple and with the child, the previous contract is sufficient and not need to re-contract (Ayatollah Tabrizi, G.A.q / 480) Ayatollah Nouri Hamadani also believe the absurdity of this condition (G.A.q / 258) Ayatollah Makarem Shirazi, sentence to nullity this condition and truth of marriage (as) Ayatollah Mousavi Ardabili has made a statement saying the problem in this way: "The condition of not entry to be absolute and permanent is problem, but as a temporary, which is not very long, there is no problem"

However, other scholars have believed in the veracity of such condition (Ayatollah Azam Behjat and Fazel Lankarani, the same) in assuming the correctness of such a condition, there is difference that by compliance of wife for other sexual intercourse other than entery how much dowry is on couple's obligation. Ayatollah Bahjat believes in all dowries by entry, so in the assumption woman is not deserved to all dowries, Ayatollah Safi Golpayegani considers woman is deserved of all dowry, Ayatollah Azam Sistani and Fazel Lankarani considers woman is deserved complete dowry, but if the couple divorce before his entry, the female must return half of dowry to her husband.

5) The right of lien:

According to article 1085 of the Civil Code, women can refuse of tasks that have in front of husband until dowry isn't given her. Lawyers have considered meaning of the responsibilities of wife that can refuse till receiving the dowry, compliance in certain legal meaning means sexual duties (Shahidi, 2003, 3 / 175-176, Safai and Emami $2004,178 / 1)$ 


\section{6) The right to contraception:}

Many women for contraception and conception in the womb use pills or inject or they put a device within their own vulva. If preventing pregnancy by these objects not cause defective and paralysis of member and sterility, it is permissible, because temporarily prevent conception is not problem. Of course if this act does not have harm for the female body. But the woman has no right to continue this work and always sterile self, because a plurality of Muslim generation is desirable.

Yes, if pregnancy has risk or loss of body for women, she can prevent absolutely as long as the pregnancy is harmful (Ayatollah Golpayegani, 2003, 173/2) the harm means that criterion to prevent permanently is personal loss, not typical, and if doctor ensures that pregnancy is risky or severe constriction for her, she can generally close the fallopian tubes, as long as there is no other way to ward off danger (Ayatollah Araki, 1994, 1/251) The doctor must in addition to have expertise in this issue be authentic. Whether he is done the work under the Sharia (Imam Khomeini, 2002, 188/1)

It should be noted that such economic problems, social, numerous children, family planning and aging cannot be the reason of permanent cessation for pregnancy (the same, 449/3) and even in the case that woman has periodic insanity with pregnancy, if sterilization of woman is caused interrupt generation, it is not permissible (the same, 281)

But tubal ligation is legitimate and permissible in mothers that if they become pregnant, the resulting fetus has defects like congenital deafness or genetic disorders. But one cannot make such families who have children with birth defects or diseases such as thalassemia etc., to close pipelines and force them to do so is not religious (Ayatollah Mousavi Ardabili, 1997, 448/1)

Prevention is permissible if involves unlawful act like look and touch or look of non -husband on genitals (Ayatollah Azam Tabrizi, 1999, 475/1, Khoi, 1416 AH, 322/1), but if becoming pregnancy follows unconventional stiffness and constriction and prevention is only through putting devises to female genitals by a doctor, it may be such a thing is permissible (Ayatollah Khoi, 1991, 1/121)

The permission of the husband in applying this right is not necessary and wife without permission of husband can prevent where pregnancy would harm forever (the Ayatollah Azam Khoi, 1416 AH, 358/1, Gulpaygani, 1993, 2/173), but according to some sources, in permanent preventing, precaution is obliged that the woman with the permission of husband do it (Ayatollah Golpayegani, $1419 \mathrm{AH}, 54 / 2)$ and in the view of Ayatollah Khamenei a woman who is healthy can prevent pregnancy only with the consent of the husband, temporarily with drugs and devices that can be prevented conception (1420 AH, 63/2)

Contraception is a woman's right to use this right must not pay anything to the man. But if a woman taking pills to make the sperm to be annulled, if that is known sperm was signed, she committed unlawful work and should pay compensation. And if she eats pills to not become pregnant, if not harmful for her and does not cause infertility in women, there is no problem and must not pay money that by eating pills prevent it, especially with the consent of husband (Ayatollah Golpayegani, 1993, 244/3)

7) The right not to comply in the case of the unconventional demand of husband and fear of risk:

One of the legal duties of the wife is compliance of couple and faith of the husband has virtue that is considered jihad of woman and has the jihad reward for woman. Therefore, Muslim lady who emphasized in doing Islamic duties and must pay attention to spousal relationship with her husband and refuse the sin and not do the husband's rights and not be against her husband. So as it is said that if a husband requests from his wife who is reading Quran, the woman is obliged to leave it and satisfies her husbands need. And engage in the recommended practice is not an excuse for leaving husband's request (Ayatollah Tabrizi, 1999, 449/1)

Obviously, the man is right in this direction has conventional behavior and complies good companionship with his wife (Ayatollah Golpayegani, 1419 AH, 21/2) and man cannot asked his wife sexual in unconventional ways and makes her harassment. And

if such a request is done, the woman is not obliged to comply. For example, request her when his wife lost one of his close relatives, or has severe physical fatigue or boredom, is unconventional request. Because in this case woman does not have the mental readiness for compliance.

If the woman does not follow husband in this unusual cases, man doesn't have the right to divorce her and if divorces her, the wife can claim all their rights in court. According to sentence in the verse "it is on responsibility of men worthly" (Nisa / 19) sexual relationship must not bother female and least disruptive is out of being famous. And the verse "and duties on women responsibility" (Baghare/ 228) the rights of each of the spouses on 
the other, its popularity is bound. Therefore, any claim that caused harassment and pressure on the other side and out of the ordinary and known way among them will not be legitimate. If the nature of man is in such a way that he does not satisfy with a number of conventional compliance .

And on the other hand, due to the pain that woman has in her hands and waist caused by rheumatism, respond to this need is hard for her husband, the woman's husband should also bear in mind this state of woman and to not exceed the standard extent. The woman has no right of unwarranted excuses. For example, she is not allowed because the child must feed completely two years avoid the sex with her husband (Khomeini, 2002, 207/3)

Another thing that a woman has the right not to compliance is in a place that sexual is with fear for woman, which in these cases, the woman has the right to answer in the negative to question of man and away from the risk. For example, where husband is in contagious disease and wife knows that by sleeping and socializing, the disease spread to her, the woman has the right not compliance and couple cannot refuse giving alimony due to not compliance (Ayatollah Golpayegani, 1993, 195/2) when man has AIDS, women for self-defense has the right to refuse sexual intercourse with him (Ayatollah Tabrizi, G.A. AH)

Also according to Article 1115 of the Civil Code, women were allowed in the case of fear refrain the compliance and despite the husband's request, citing fear of physical harm, financial or honor refuses from back home that required general and specific compliance. As for the meaning of fear of loss in this matter, the opinions are different. Legal Department judiciary in advisory opinion No. 7/3086 on 2007 announce that use of the word fear of loss by the legislator in Article 1115 of the Civil Code of the law, not far from its literal meaning and purpose, fear of entry material or physical harm or honor to the wife if the husband is with her in a housing.

If woman due to dignity not have reason, the judge can avoid the verdict of returning wife to husband house rely on circumstantial evidence and the UAE which guarantees return to the husband house and according to Article 199 of the Civil Procedure Code in the public and revolutionary courts, (G.a.q / 398)

\section{Conclusion}

With regard to the rights that was mentioned in this writing for a married woman, this result is that, although in the verses and hadiths, woman is considered calming the man but that does not mean that the purpose of the creation of woman is relaxation to man and is like a means that is in hands of man without any protest against her husband. As in Jewish and Christian culture, woman was considered as a vehicle for pleasure and lust and serving the man that always and without any protest should be in the hands of husband. But both man and woman have equal rights in marriage and no one has the right to abuse another, but must help to this issue by respecting the rights of marriage of each other, that is the most important cause of family stability.

\section{References}

Araki, M. A. (1993). questions join to thesis, Ghom, the center of Islamic Publications Bureau.

Araki, M. A. (1994). questions, Ghom, famous publication.

Emami, A., \& Safai, H. (2004). Family Law, Tehran.

Horr Ameli, Mohammed ibn Hasan, Wasael Al-shiea, Beirut, Press Center of Darolhaya Alteras Alarabi, 2012 $\mathrm{AH}$.

Hosseini Khamenei, Seyed Ali, Ajubeh Alesteftayat, Beirut, Al Dar al islamiya publication, 1420 AD.

Khoi, Seyed Abul Ghasem, Maniya Alsayel, Ghom, publisher, author, 1991.

Khoi, Seyed Abul Ghasem, Manya Alsalehin, Ghom, published by Madine Alalam, 1410 AH.

Khoi, Seyed Abul Ghasem, Serat Alnejah, Ghom, published by Bargizide, 1416 AH.

Kleeni, Kafy, Ghom, publication of Darolketab Islamiyah, the second edition in 2009.

lankarani, Mohammad Fazel, Jameolmayel, Ghom, Amir poblications, 1997.

Makarem Shirazi, Naser, a set of new questions, Ghom, school publications of Imam Ali ibn Abi Talib (AS), 1996.

Mousavi Ardabili, Seyed Abdul Karim, questions, Ghom, Nejat Publications, 1997.

Mousavi Khomeini, Seyed Ruhollah, Due process from the viewpoint of Imam Khomeini, Ghom, Shakoori Press, $1986 \mathrm{p}$.

Mousavi Khomeini, Seyed Ruhollah, questions, Ghom, Islamic Publications Office, 2002.

Nouri Hamadani, Hussein, a thousand and one legal issue, Ghom, published by the Institute of Mahdi (aj), 1997. 
Questions treasures of Justice, Bureau of Education of Clergymen and drafting of legal texts, judicial training deputy.

Safi Golpayegani, Lorfillah, Assembly of Islamic Law, Ghom, published by Darolghoran al-Karim, Fourth Edition, 1993.

Safi Golpayegani, Lotfollah, Jame Alahkam, Ghom, publishing of Masume (AS), 1419 AH.

Samarghandi Salma Masoud bin Ayyash, interpretation of orgy, Tehran, publishing of Almaktabah Aleslamiya, 1985.

Shahidi, Mefdi, Civil Rights, Tehran, 2003.

Siuyuti, Jalaladdin, Aldar Almansur, Jeddah, publishing Daralmarefeh, 1986.

Tabrizi, J. (1999). new questions, Ghom, Publishing of server.

\section{Copyrights}

Copyright for this article is retained by the author(s), with first publication rights granted to the journal.

This is an open-access article distributed under the terms and conditions of the Creative Commons Attribution license (http://creativecommons.org/licenses/by/3.0/). 